\title{
Extremely Small Multimode Interference Couplers and Ultrashort Bends on InP by Deep Etching
}

\author{
L. H. Spiekman, Y. S. Oei, E. G. Metaal, F. H. Groen, I. Moerman, and M. K. Smit
}

\begin{abstract}
We realized the smallest integrated optical multimode interference (MMI) couplers to date by etching through the quaternary guiding layer, maximizing the lateral index contrast, and thus obtaining a sufficient number of guided modes for proper operation despite the small size. Results include a $107 \mu \mathrm{m}$ long $3 \mathrm{~dB}$ coupler with $0.9 \mathrm{~dB}$ excess loss and $0.2 \mathrm{~dB}$ unbalance, and a $216 \mu \mathrm{m}$ long cross coupler with $2.0 \mathrm{~dB}$ excess loss and $-28 \mathrm{~dB}$ crosstalk (TE). We also succeeded in making waveguide bends with a record bending radius of only $30 \mu \mathrm{m}$ and negligible radiation loss.
\end{abstract}

\section{INTRODUCTION}

$\mathbf{O}$ PTICAL couplers are important components in photonic integrated circuits. The multimode interference (MMI) coupler [1], [2] is a good candidate because of its bandwidth and polarization properties and its tolerance of fabrication variations [3], [4]. Its operation has already been demonstrated in Mach-Zehnder interferometer switches [5], [6], an optical coherent receiver [7], and ring lasers [8]. In this letter, we will show the operation of miniaturized MMI couplers, which will be important devices when integration scale and production costs become an issue.

\section{COUPLER DESIGN}

Figure 1 shows the basic layout of an MMI coupler design. The MMI is simply a very wide waveguide, in which a large number of optical modes can propagate. These modes are excited by the field entering the MMI through the access waveguide, the excitation coefficients being determined by the modal field shapes. They propagate through the structure with different propagation constants. It has been shown that, at certain distances, the local interference pattern produces one or more so-called self-images of the input field, thus making cross or $3 \mathrm{~dB}$ coupler operation possible [1].

It is important that the multimode section supports a sufficient number of guided modes to make accurate imaging of the input field possible. This number is decreased by miniaturizing the MMI. It can be raised again by deep etching. By etching

Manuscript received February 16, 1994; revised April 29, 1994. This work was supported by the Innovative Research Program IOP-EO, sponsored by the Dutch Ministry of Economic Affairs.

L. H. Spiekman, Y. S. Oei, and M. K. Smit are with the Department of Electrical Engineering, Laboratory of Telecommunication and Remote Sensing Technology, Delft University of Technology, The Netherlands.

E. G. Metaal is with PTT Research, Leidschendam, The Netherlands,

F. H. Groen is with the Department of Applied Physics, Research Group for Optics, Delft University of Technology, Delft, The Netherlands.

I. Moerman is with the Department for Information Technology, University of Gent, Belgium

IEEE Log Number 9403591.

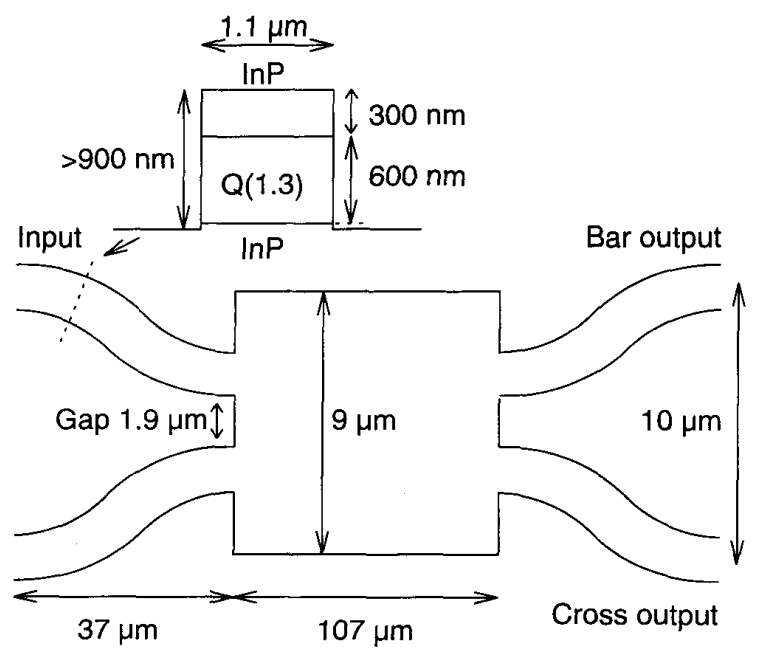

Fig. 1. Top view of Multimode Interference (MMI) $3 \mathrm{~dB}$ coupler and cross section of access waveguide.

completely through the waveguide layer, the waveguide performance becomes independent of etch depth tolerance. In our structure (Fig. 1), a lateral index step of 3.3:1 is thus obtained. It has to be kept in mind, however, that the number of modes that a structure supports laterally can be reduced by radiation into the substrate of modes with effective indices lower than the substrate index [9].

To make the MMI as short as possible, we have employed the restricted resonance mode of operation [1]. With respect to equal-length full resonance devices, this allows a wider MMI, which reduces the relative impact of width variations. The access waveguides can simply be positioned at $\frac{1}{3}$ and $\frac{2}{3}$ of the MMI width without any need for further adjustment, because of the strong confinement of the modes.

The access waveguides are $1.1 \mu \mathrm{m}$ wide, in order to avoid lithographic problems with respect to the gap size. This has the advantage of yielding them monomode, but is expected to result in considerable propagation loss. We use both a technological and a design solution for this problem: a special etching process is used in fabrication to make the waveguides as smooth as possible [10], and a width of $3 \mu \mathrm{m}$ is used all along the access waveguides, yielding them multimode. A taper to $1.1 \mu \mathrm{m}$ is applied just before the $S$-bends leading to the MMI. The $S$-bends act as mode filters for higher order modes.

We were able to make these $S$-bends very small as well, because the large etching depth diminishes radiation loss. We 


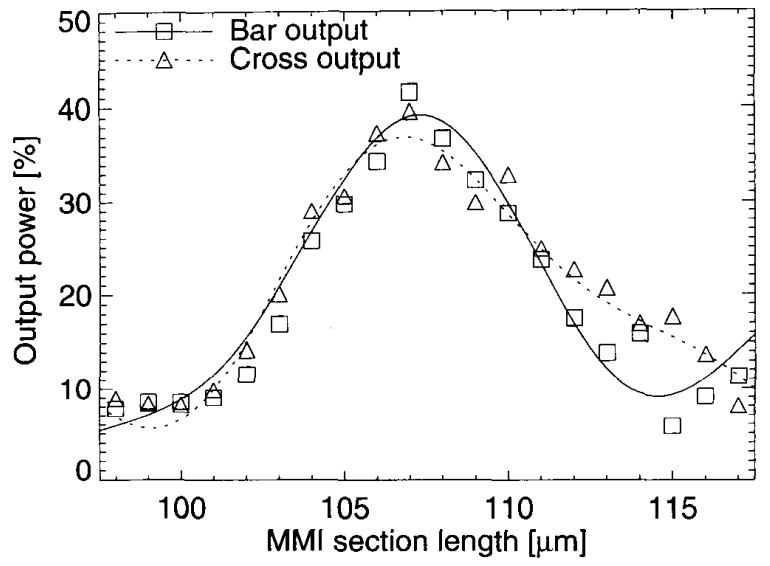

Fig. 2. Simulated and measured TE performance of $3 \mathrm{~dB}$ couplers. The points show measurements carried out at a wavelength of $1507 \mathrm{~nm}$. The lines represent a Modal Propagation simulation.

used a small but still conservative radius of $100 \mu \mathrm{m}$, and separately tested $U$-bends with radii down to $30 \mu \mathrm{m}$.

\section{FABRICATION}

We fabricated the devices in a MOVPE grown layer structure (600 nm InGaAsP, bandgap $1.3 \mu \mathrm{m} ; 300 \mathrm{~nm}$ InP top) on SI-InP substrate. A $140 \mathrm{~nm}$ RF-sputtered $\mathrm{SiO}_{2}$ layer served as an etching mask. After projection lithography, we transferred the device pattern into this layer with $\mathrm{CHF}_{3}$ reactive ion etching, and subsequently etched the wafer with $\mathrm{CH}_{4} / \mathrm{H}_{2} \mathrm{RIE}$, employing an alternate etching $/ \mathrm{O}_{2}$-descumming process to reduce polymer deposition-induced roughness. This process produces extremely smooth sidewalls and correspondingly low propagation losses, which is a matter of major concern for narrow waveguides [10].

\section{EXPERIMENTAL RESULTS}

We performed transmission measurements using microscope objectives to couple light from a $1507 \mathrm{~nm}$ Fabry-Perot laser in and out of the chip, with a pinhole shielding the photodetector from stray light and light from other nearby waveguides.

The output power of the $3 \mathrm{~dB}$ couplers measured relative to the power transmitted through straight reference waveguides is plotted in Fig. 2 as a function of the device length. The measurements are in excellent agreement with simulations based on modal analysis, in which the radiation modes are neglected. For the TE polarization, the excess $\operatorname{loss}\left(-10 \log \frac{P_{\text {cross }}+P_{\text {bar }}}{P_{\text {ref }}}\right)$ of the MMI coupler with an optimum length of $107 \mu \mathrm{m}$ is 0.9 $\mathrm{dB}$. For this device, the unbalance $\left(-10 \log \frac{P_{\text {cross }}}{P_{\mathrm{bar}}}\right)$ is only 0.2 $\mathrm{dB}$. The results for TM are comparable. The optimum device length for this polarization is $111 \mu \mathrm{m}$. The excess loss is 0.7 $\mathrm{dB}$, and the unbalance is $0.2 \mathrm{~dB}$.

The performance of the cross couplers is shown in Fig. 3. Again, the results are in excellent agreement with theory, also at details of the simulated curve. The optimal cross coupler length for TE polarization is $216 \mu \mathrm{m}$, twice as long as that of the $3 \mathrm{~dB}$ coupler, as is expected. The excess loss is $2.0 \mathrm{~dB}$, and the crosstalk is $-28 \mathrm{~dB}$. The TM results are once again

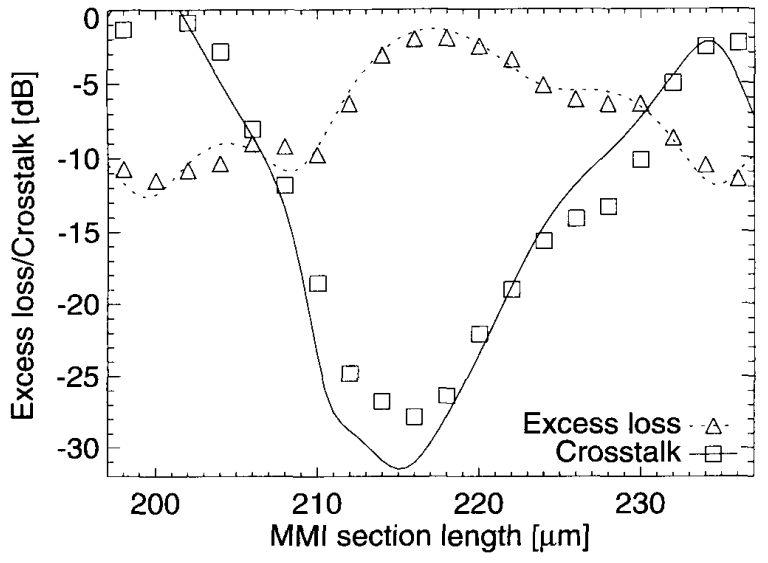

Fig. 3. Simulated and measured TE performance of cross couplers.

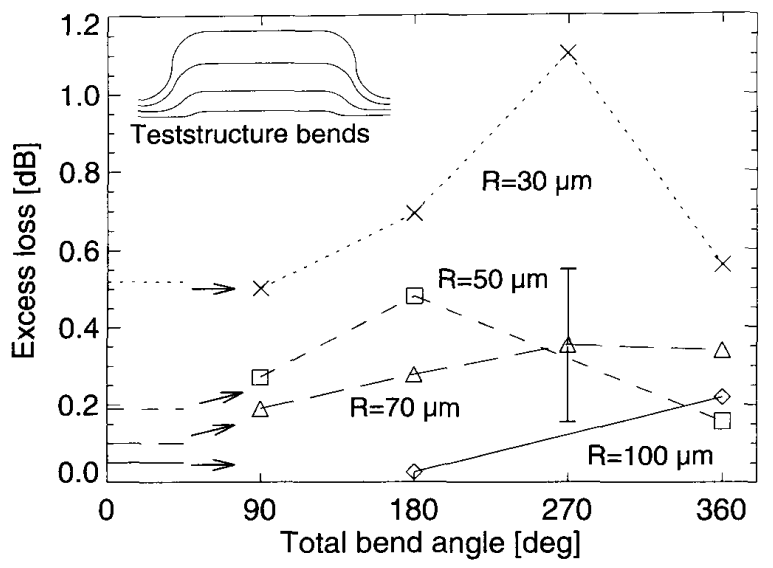

Fig. 4. Bend loss relative to straight reference waveguide loss as a function of total bend angle for a number of radii. The estimated measurement error is indicated. The horizontal lines on the left show the calculated losses on the basis of straight-to-bend and bend-to-bend junction loss.

comparable to the TE results. The optimum coupler length is shifted to $222 \mu \mathrm{m}$. The excess loss is $1.2 \mathrm{~dB}$, and the crosstalk is $-31 \mathrm{~dB}$.

We measured waveguide losses separately using cutback. The $3 \mu \mathrm{m}$ wide access waveguides used on most of the chip (total chip length $0.8 \mathrm{~cm}$ ) have propagation losses of $0.6 \mathrm{~dB} / \mathrm{cm}$ for both TE and TM. The $1.1 \mu \mathrm{m}$ wide waveguides used near the MMI couplers show losses of $6.6 \mathrm{~dB} / \mathrm{cm}$ for TE and 5.0 $\mathrm{dB} / \mathrm{cm}$ for TM. The latter values agree excellently with FabryPerot contrast measurements (differences within $0.5 \mathrm{~dB} / \mathrm{cm}$ ). Agreement was worse for the $3 \mu \mathrm{m}$ waveguides, probably due to their multimode nature. As expected, the figures for the narrow waveguides are considerably higher than those for the wide waveguides, but they have been kept within reasonable bounds by the etching/descumming process. We conservatively employed $50 \mu \mathrm{m}$ long linear tapers to connect the waveguide sections of different widths. Taper losses were assessed separately for taper lengths from 10 to $50 \mu \mathrm{m}$, and were all negligible $(<0.1 \mathrm{~dB})$.

To determine bend losses, we separately tested $U$-bends with radii down to $30 \mu \mathrm{m}$ and total bend angles up to $360^{\circ}$. 


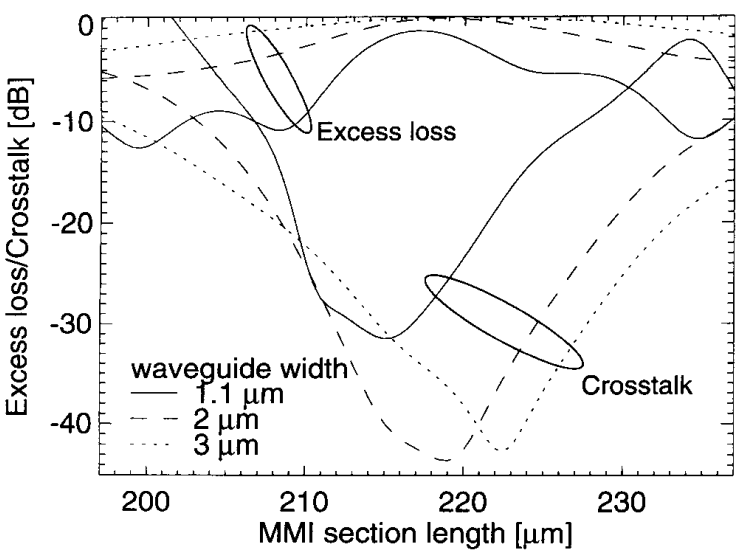

Fig. 5. Simulated performance of a cross coupler for different access waveguide widths. As the access waveguides become wider, the coupler becomes more tolerant to fabrication variations.

(See Fig. 4.) The expected linear increase of loss with bend angle, i.e. the amount of waveguide bend measured, was not observed, indicating that losses distributed continuously along the bend do not constitute the predominant loss mechanism. From this, we may infer that radiation loss is very small, at most $0.2 \mathrm{~dB} / 90^{\circ}$. The losses measured are in agreement with what is expected on the basis of modal field mismatch at the straight-to-bend and bend-to-bend junctions.

\section{DISCUSSION}

We have fabricated very short MMI cross couplers $(216 \mu \mathrm{m})$ and $3 \mathrm{~dB}$ couplers $(107 \mu \mathrm{m})$ and extremely sharp waveguide bends $(R=30 \mu \mathrm{m})$ which we believe to be the smallest MMI couplers and bends made on InP to date.

The loss in the waveguide bends is negligibly small, making any required coupler input spacing possible with low loss. Losses of the MMI couplers are slightly higher than those of previously published components $[1,4,11]$. The unbalance and crosstalk values are excellent. The couplers, however, are weakly polarization dependent.

Figures 2 and 3 show that the performance is heavily dependent on the length of the devices. The optimal length of an MMI being in first order approximation proportional to the square of the MMI width [12], this leads to a high susceptibility for lithographic width variations. A deviation of as little as $0.1 \mu \mathrm{m}$ will cause an additional loss of $1 \mathrm{~dB}$. This requires very tight control of the lithography. Tolerance requirements can be relaxed by using wider input waveguides, as illustrated in Fig. 5. This will also lead to reduction of the excess loss and better polarization independence. The consequence, however, is a larger device length. We are presently investigating an optimal compromise between the different requirements.

\section{ACKNOWLEDGMENT}

The work of J. W. M. van Uffelen, A. H. de Vreede and C. R. de Boer in fabricating the devices is gratefully acknowledged.

\section{REFERENCES}

[1] L. B. Soldano, F. B. Veerman, M. K. Smit, B. H. Verbeek, A. H. Dubost, and E. C. M. Pennings, "Planar monomode optical couplers based on multimode interference effects," J. Lightwave Technol, vol. 10, pp. 1843-1849, Dec. 1992.

[2] E. C. M. Pennings, R. van Roijen, B. H. Verbeek, R. J. Deri, and L. B. Soldano, "Ultracompact multimode interference waveguide devices," in Annual Meeting of the IEEE Lasers and Electro-Optics Society, (San José, USA), Nov. 1993, invited paper IO2.1.

[3] M. K. Smit, "Branching, radiative and self-imaging elements for use in $M \times N$ couplers," in Proc. 6th Conf. on Integr. Opt. ECIO'93, (Neuchâtel, Switzerland), April 18-22 1993, pp. 14.1-14.3.

[4] L. B. Soldano, M. Bachmann, P. A. Besse, M. K. Smit, and H. Melchior, "Large optical bandwidth of InGaAsP/InP multi-mode interference 3dB couplers," in Proc. 6th Conf. on Integr. Opt. ECIO'93, (Neuchâtel, Switzerland), April 18-22 1993, pp. 14.10-14.11.

[5] J. E. Zucker, K. L. Jones, T. H. Chiu, B. Tell, and K. Brown-Goebeler, "Polarization-independent electro-optic waveguide switch using strained InGaAs/InP quantum wells," in Integrated Photon. Resear. (IPR '92), Postdeadline Papers, pp. 21-24, New Orleans, Louisiana, April 13-16, 1992.

[6] M. Bachmann, M. K. Smit, P. A. Besse, E. Gini, H. Melchior, and L. B. Soldano, "Polarization-insensitive low-voltage optical waveguide switch using InGaAsP/InP four-port Mach-Zehnder interferometer," in OFC/IOOC'93 Tech. Digest, vol. 4, San Jose, California, pp. 32-33, Feb. 21-26 1993.

[7] R. J. Deri, et al., "Ultracompact monolithic integration of balanced polarization diversity photodetectors for coherent lightwave receivers," IEEE Photon. Technol. Lett., vol. 4, pp. 1238-1240, Nov. 1992.

[8] M. J. N. van Stralen, et al., "Design and fabrication of integrated InGaAsP ring lasers with MMI-outcouplers," in Proc. 6th Conf. on Integr. Opt. ECIO'93, pp. 2.24-2.25, (Neuchâtel, Switzerland), April 18-22 1993.

[9] R. J. Deri and E. Kapon, "Low-loss III-V semiconductor optical waveguides," IEEE J. Quantum Electron., vol. 27, pp. 626-640, Mar. 1991.

[10] L. H. Spiekman, et al.:, "A new fabrication process for very low-loss narrow-width InGaAsP/InP waveguides," in Proc. 6th Conf. on Integr. Opt. ECIO'93, pp. 2.30-2.31, (Neuchâtel, Switzerland), April 18-22 1993.

[11] E. C. M. Pennings, et al. "Ultra-compact, low-loss directional coupler structures on InP for monolithic integration," in Proc. 17th Eur. Conf. on Opt. Comm. (ECOC'91), (Paris), Sep. 9-12, 1992, pp. 405-408.

[12] P. A. Besse, M. Bachmann, H. Melchior, L. B. Soldano, and M. K. Smit, "Optical bandwidth and fabrication tolerances of multimode interference couplers," accepted for publication in J. Lightwave Technol., 1994. 